Petroleumäther mit dem Fett über die alkoholische Fuchsinlösung. Letztere wird so oft ( $4-5 \mathrm{mal})$ mit Petroleumäther ausgeschüttelt, bis dieser beim Verdunsten keinen Rückstand von gelöstem Fett mehr hinterlässt, sodann im Scheidetrichter vorsichtig abgezogen und mit überschüssiger Ammoniaklösung versetzt. Das sich abscheidende schwefelsaure Ammoniak wird durch Filtration der Flüssigkeit entfernt und das entfärbte oder schwach gelblich gefärbte Filtrat in tarirter Platin- oder Glasschale zur Trockne verdunstet. Man gewinnt so $80-85 \%$ des zur Färbung angewendeten Materiales.

Zur Bestimmung des Schmelzpunktes von Fetten benutzt 0 skar Kellner*) eine gerade, capillare Röhre mit kenlenförmiger Erweiterung an dem einen Ende. Letztere wird zugeschmolzen, und das Capillarrohr, während der keulenförmige Theil noch nicht ganz abgekühlt ist, in das flüssige Fett getaucht. Fon demselben lässt man eine $3-5 \mathrm{~cm}$ lange Schicht aufsaugen und taucht diesen Theil der Röhre rasch in sehr kaltes Brunnenwasser, wobei das keulenförmige Ende über der Oberfläche bleibt. Das Fett erstarrt alsbald und steigt nicht mehr dem erweiterten Theile zu, was man auch leicht durch Schliessen der capillaren Oeffnung mit dem Finger verhindern kann. Wird alsdann die Capillare in bereits vorgewärmtes Wasser gebracht und letzteres langsam weiter erwärmt, so steigt beim Beginn der Schmelzung die Fettsänle momentan in den luftrerdünnteu Raum der keulenförmigen Erweiterung. Dieser Punkt lässt sich natürlich leicht beobachten.

\title{
Zur Prüfung der Schmieröle ${ }^{* *}$ ) und eventuellen Bestimmung
} ihres Säuregehaltes gibt E. L a u g i $\left.\mathrm{r}^{*}{ }^{* * * *}\right)$ mehrere Methoden an.

1. In einer $100 \mathrm{cc}$ fassenden Glasflasche werden $10 \mathrm{~g}$ Oel mit $50 \mathrm{ce} 90$ procentigen Alkohols gemischt. Ist der anfänglich milchige Alkohol bei einer Temperatur von $30^{\circ}$ klar geworden, so decantirt man ihn in ein tarirtes Schälchen und wäscht das Oel noch wiederholt mit gleichen Mengen Alkohol. Gewöhnlich genügen 4 Waschungen mit zusammen $200 \mathrm{cc}$ Alkohol. Es ist wünschenswerth, immer unter denselben Umständen zu arbeiten, um so leicht für diejenige Menge fetten Oeles,

*) Landwirthschaftl. Versuchsstationen 25, 45; vom Verfasser eingesandt.

**) Vergl. diese Zeitschr. 13, 339; 17, 387, 510; 18, 546; 19, 116.

***) "Essai des huiles de graissage" Bull. de la soc. industrielle de Marseille; vom Verfasser eingesandt. 